\title{
Improvements of calibration strategies for SIMS isotope analysis of apatite - IAG Young Scientist Medal Lecture
}

\author{
ALICJA WUDARSKA ${ }^{1,2}$, EWA SLABY ${ }^{1}$, MICHAEL \\ WIEDENBECK ${ }^{2}$ AND FRÉDÉRIC COUFFIGNAL ${ }^{2}$ \\ ${ }^{1}$ Institute of Geological Sciences, Polish Academy of Sciences \\ ${ }^{2}$ GFZ German Research Centre for Geosciences \\ Presenting Author: ndgiera@cyf-kr.edu.pl
}

Two pioneering isotope research studies have recently shown that oxygen $\left(\delta^{18} \mathrm{O}\right)$ and chlorine $\left(\delta^{37} \mathrm{Cl}\right)$ isotope compositions of minerals from the apatite group $\mathrm{Ca}_{10}\left(\mathrm{PO}_{4}\right)_{6}(\mathrm{~F}, \mathrm{Cl}, \mathrm{OH})_{2}$ may prove useful in the investigation of magmatic and metamorphic samples [1,2]; heretofore $\delta^{18} \mathrm{O}$ and $\delta^{37} \mathrm{Cl}$ signatures have been predominantly studied in bioapatite and extra-terrestrial materials, respectively. Apatite crystals in terrestrial rocks are usually small or heterogeneous, and in such cases in situ isotope analysis using secondary ion mass spectrometry may be the only option. Addressing the lack of well-characterized reference materials and standardized analytical protocols for isotope ratio analyses of apatite, we have undertaken this work to improve future SIMS data quality. Based on the datasets collected from new reference materials [3,4], we noted a small, but significant crystallographic orientation effect and a correlation of instrumental mass fractionation factor with $\mathrm{Cl}$ concentration in $\delta^{37} \mathrm{Cl}$ measurements. Such effects were not observed for $\delta^{18} \mathrm{O}$ analyses. In both isotope systems, however, the biggest challenge for SIMS data accuracy are the offsets between isotope compositions of the reference materials determined in multiple gas source isotope ratio mass spectrometry laboratories.

Due to the different closure temperature of the U-Pb system for apatite, it can either complement zircon or may even serve as the sole means for the age determination of some lithologies. Therefore, we are developing new reference material(s) for $\mathrm{U}-\mathrm{Pb}$ dating of apatite. Although this part of our study is in its early stage, we have already selected an apatite sample extracted from a late Archean monzogranite having acceptable concentrations of radiogenic $\mathrm{Pb}$ and low common $\mathrm{Pb}$ for further study.

We acknowledge and are grateful for the support of our coauthors involved in the reference materials development $[3,4]$. This research was supported by Polish NCN grant no. 2013/11/B/ST10/04753, the IGS PAS grant for early career researchers, the International Association of Geoanalysts (Geoanalytical Research and Networking Grant), the COST Action TD1308 “ORIGINS" and DAAD.

[1] Bruand et al. (2019), Geochim Cosmochim Acta 255, 144162. [2] Kusebauch et al. (2015), Contrib Mineral Petrol 170, 34. [3] Wudarska et al. (2020), EGU2020-18841. doi:10.5194/egusphere-egu2020-18841. [4] Wudarska et al. (2021), Geostand Geoanal Res. doi:10.1111/ggr.12366. 